\title{
Production of a monoclonal antibody reactive with human dendritic reticulum cells and its use in the immunohistological analysis of lymphoid tissue
}

\author{
M NAIEM, ${ }^{*}$ J GERDES, $\dagger$ Z ABDULAZIZ, ${ }^{*}$ H STEIN,$\dagger$ D Y MASON* \\ From the *Nuffield Department of Pathology, John Radcliffe Hospital, Oxford, and the †Institute for \\ Pathology, Christian Albrechts University, Kiel, West Germany
}

SUMmarY A murine monoclonal antibody (designated R4/23) which reacts strongly with human dendritic reticulum cells (DRC) is described. Immunoperoxidase staining of tissue cryostat sections revealed that this antibody reacts strongly with DRC in lymphoid follicles (both primary and secondary), and also weakly with marginal zone splenic B cells and with some peripheral follicular mantle B lymphocytes in lymph node cortical follicles. The value of antibody R4/23 is that it allows the distribution of DRC in reactive and neoplastic lymphoid tissue to be clearly delineated. Of particular interest is the fact that all cases of follicular lymphoma of germinal centre cell origin are consistently accompanied by a proliferation of DRC, even when the neoplasm is present in non-lymphoid tissue-for example, in the kidney. In contrast, DRC in B cell lymphomas of non-germinal centre origin are partially or totally obliterated.

In 1927 Maximov described a population of "embryonale nichtspeichernde Reticulumzellen" ("embryonal non-phagocytic reticulum cells") which are present within the cortical follicles of peripheral lymphoid tissue. ${ }^{1}$ Since this original description these cells, usually referred to as "dendritic reticulum cells" (DRC), have been the subject of numerous electron microscopic and cytochemical studies. ${ }^{2-6}$

DRC are found in primary lymphoid follicles and in the germinal centres of secondary lymphoid follicles, where their long branching processes form a delicate three-dimensional network within which germinal centre lymphoid cells are enmeshed. ${ }^{2} 3$ DRC have been shown by autoradiographic and immunohistological techniques to have a high affinity for immune complexes. ${ }^{7}$ They thus appear to play a primary role in the trapping of antigen within germinal centres. They may also be involved in B cell homing since neoplastic germinal centre cells in cases of follicular lymphoma can be shown by light and electron microscopy to accumulate within a meshwork of DRC.

Since DRC (and especially their long cytoplasmic processes) are difficult to recognise by conventional light microscopy attempts have been made to reveal them using enzyme histochemical techniques. 5'-

Accepted for publication 2 August 1982 nucleotidase has proved the most suitable enzyme for this purpose, high levels of activity being detectable on the surface membrane of DRC. ${ }^{8}{ }^{9}$ However the value of this enzyme as a marker of DRC is limited by the fact that it is also present on the surface of follicular mantle cells and some germinal centre cells ${ }^{8}$ and also by the susceptibility of the 5 -nucleotidase histochemical reaction to technical artefacts (own unpublished observations). There is hence a need for a more specific technique which will allow DRC to be identified and thus enable abnormalities in their distribution in different disease states to be investigated.

In the present paper we describe the production of a monoclonal antibody which reacts strongly with human dendritic reticulum cells (and also weakly with a subset of B cells). This antibody has already proved of great value in analysing the distribution of DRC in reactive lymphoid tissue and in lymphomas of germinal centre origin. It should also prove of value in the future for the isolation of DRC in a high degree of purity from human lymphoid tissue.

\section{Material and methods}

TISSUES

Fresh tissue samples were obtained from surgical biopsy or tonsillectomy specimens taken in the John 
Radcliffe Hospital, Oxford or the University Hospital, Kiel. Tissue slices approximately $5 \mathrm{~mm}$ thick were snap-frozen and stored in liquid nitrogen until cryostat sectioning.

\section{CELL SUSPENSIONS}

Suspensions of peripheral blood lymphocytes, granulocytes, monocytes and tonsillar lymphocytes were prepared by gradient centrifugation as described previously. ${ }^{10}$

PRODUCTION OF MONOCLONAL ANTI-DRC ANTIBODY

This antibody was produced during a fusion experiment aimed at raising monoclonal antibodies specific for human $\mathrm{C} 3$ receptors. BALB/c mice were immunised by a schedule previously used for raising polyclonal rabbit antiserum against human $\mathrm{C} 3$ receptors. ${ }^{10}$ The antigen consisted of sheep red cells which had been incubated sequentially with rabbit antisheep cell antiserum, followed by C3-deficient rabbit serum. These EAC were then incubated in a complement receptor-rich $\mathrm{KBr}$ extract of normal human tonsil cell membranes in order to coat them with $\mathrm{C} 3$ receptor.

The mouse used for the fusion experiment which produced the anti-DRC antibody had received two intravenous injections of $\mathrm{C} 3$ receptor-coated red cells before receiving a final intravenous immunisation. Four days later $10^{8}$ spleen cells were fused with $10^{7}$ NS-1 myeloma cells using polyethylene glycol as fusing agent. ${ }^{11}$ The cells were cultured in RPMI 1640 medium, supplemented with $10 \%$ fetal calf serum, glutamine, HAT (hypoxanthine, aminopterin, thymidine) and antibiotics at $37^{\circ} \mathrm{C}$ in humidified air containing $5 \% \mathrm{CO}_{2}$ after distribution into two 24-well Costar plates.

Twelve days after fusion the supernatants were screened by immunoperoxidase staining (see above) on human tonsil sections. A variety of different immunohistological labelling patterns were observed. Supernatants from two wells however showed identical reactions, both staining a meshwork within germinal centres but not cells outside lymphoid follicles. One of these cultures (designated $\mathbf{R} 4 / 23$ ) was grown up in a tissue culture flask and cloned by limiting dilution on BALB/c spleen feeder cells in a Microtitre plate. The cell line was also grown as an ascitic tumour in pristane-primed BALB/c mice.

IMMUNOHISTOLOGICAL REAGENTS

Peroxidase-conjugated rabbit antimouse Ig antiserum was obtained from Dakopatts a/s. Diaminobenzidine tetrahydrochloride was obtained from Sigma Chemical Co. Tris-buffered saline (TBS) was prepared by adding a tenth volume of $0.5 M$ Tris $\mathrm{HCl}$ buffer (pH 7.6) to $0.15 \mathrm{M}$ saline.

Monoclonal antibody specific for human $\mathrm{C} 3 \mathrm{~b}$ receptor was prepared as described previously. ${ }^{12} \mathrm{~B}$ cells in human lymphoid tissue sections were detected using monoclonal anti-IgD, ${ }^{13}$ monoclonal anti-IgM (Seward Laboratories) or a monoclonal antibody (To15) specific for B cells raised in the authors' laboratory (to be published). $\mathrm{T}$ cell areas were identified using monoclonal antibodies $\mathrm{UCHT}^{14}$ or OKT11 (Ortho Diagnostics). Monoclonal antibody to human $\mathrm{C} 3 \mathrm{~b}$ was obtained from Bethesda Research Laboratories.

TISSUE SECTION PREPARATION

Cryostat sections $(5-10 \mu \mathrm{m})$ were picked up on gelatin coated slides and dried for 4-18 $\mathrm{h}$ in the 음 vacuum chamber of a freeze drying apparatus. After fixation for $\mathbf{1 0} \mathrm{min}$ in acetone at room temperature $T$ they were air dried and then either stained immedi- 응 ately by the immunoperoxidase procedure (see below) or wrapped in aluminium foil and stored at $₹$ $-20^{\circ} \mathrm{C}$.

IMMUNOPEROXIDASE STAINING

Monoclonal antibodies (see above) were applied to dry cryostat sections. Culture supernatants containing monoclonal antibodies were used undiluted. Purified monoclonal antibodies or ascitic fluid samples containing monoclonal antibodies were tested over a range of dilutions on tissue sections and subsequently used at their optimal concentrations.

After $30 \mathrm{~min}$ incubation with antibody at room temperature in a covered chamber, sections were washed in TBS, and incubated for a further $30 \mathrm{~min}$ 응 with peroxidase-conjugated antimouse $\operatorname{Ig}(1 / 5-1 / 50)$ diluted in TBS to which normal human serum had been added (at a final dilution of 1/3-1/25) in order to $ᄋ$ block reactivity against human Ig. Sections were then washed in TBS before incubation with 응 diaminobenzidine $(0.5 \mathrm{mg} / \mathrm{ml})$ and $\mathrm{H}_{2} \mathrm{O}_{2}(0.01 \%)$ 方 diluted in TBS. ${ }^{15}$ The peroxidase reaction was terminated by washing in buffer or tap water after $N$ 5-10 min and sections were counterstained with haematoxylin before mounting for microscopic examination.

IMMUNOFLUORESCENT STAINING OF

CELL SUSPENSIONS

Immunofluorescent staining of cell suspensions was $\stackrel{\mathscr{Q}}{?}$ performed as described previously by Gerdes et al..$^{10}$

ANALYSIS OF IG CLASS OF MONOCLONAL ANTIBODY R $4 / 23$

The Ig class of this antibody was kindly analysed by Dr P Appleby by the Ouchterlony method. 
Results

CHARACTERISTICS OF ANTIBODY R4/23

The monoclonal antibody $R 4 / 23$ was shown by Ouchterlony immunodiffusion to be an IgM kappa antibody. The cell line producing the antibody has proved stable during several weeks of in vitro culture and can consistently be recovered from the frozen state. In pristane-primed BALB/c mice the cell line produces an ascitic tumour secreting antibody R4/23.

\section{IMMUNOCYTOCHEMICAL REACTIONS OF}

ANTIBODY R4/23

Non-neoplastic cells and tissues

Antibody R4/23 was tested by indirect immunofluorescence against peripheral blood mononuclear cells and granulocytes and against tonsillar lymphocytes with negative results. A wide variety of human tissues were tested using the immunohistological procedure. The majority of samples gave negative staining reactions. However lymphoid tissue (spleen, lymph node and lymphoid areas in tissues such as gastrointestinal mucosa) consistently gave strong staining reactions, consisting of a meshlike pattern in both primary and second lymphoid follicles (Fig. 1). In the germinal centres of secondary follicles the network revealed by R4/23 was present throughout the entire structure, including the centroblast-rich zone, although this region was often less strongly stained than the centrocyte-rich area. At a higher magnification it was evident that the dendritic staining pattern seen in secondary follicles penetrated beyond the germinal centres into the mantle zone of small lymphocytes (Fig. 2).

This staining pattern strongly suggested that antibody R4/23 reacts with DRC. This interpretation was supported by comparing the reactions of lymphoid follicles stained with $\mathrm{R} 4 / 23$ with those obtained using antibodies specific for IgM, IgG, IgA and $\mathrm{C} 3 \mathrm{~b}$ (all of which are present within the immune complexes bound to $\mathrm{DRC}^{16}$ ) and also for $\mathrm{C} 3$ receptors (present on $\mathrm{DRC}^{17}$ ).

It was evident from this comparison that there was a close parallelism between the reaction for these three markers. This was particularly obvious when abnormal follicles were examined in which the diffuse network of DRC revealed by $\mathrm{R} 4 / 23$ contained negative lacunae (Fig. 3).

In addition to the strong staining of presumptive DRC, antibody R4/23 gave weak surface staining of small lymphoid cells at the periphery of mantle zones in lymph node cortical follicles. Staining of splenic tissue sections with antibody R4/23 showed intense staining in a DRC-like pattern of $B$ cell follicles.

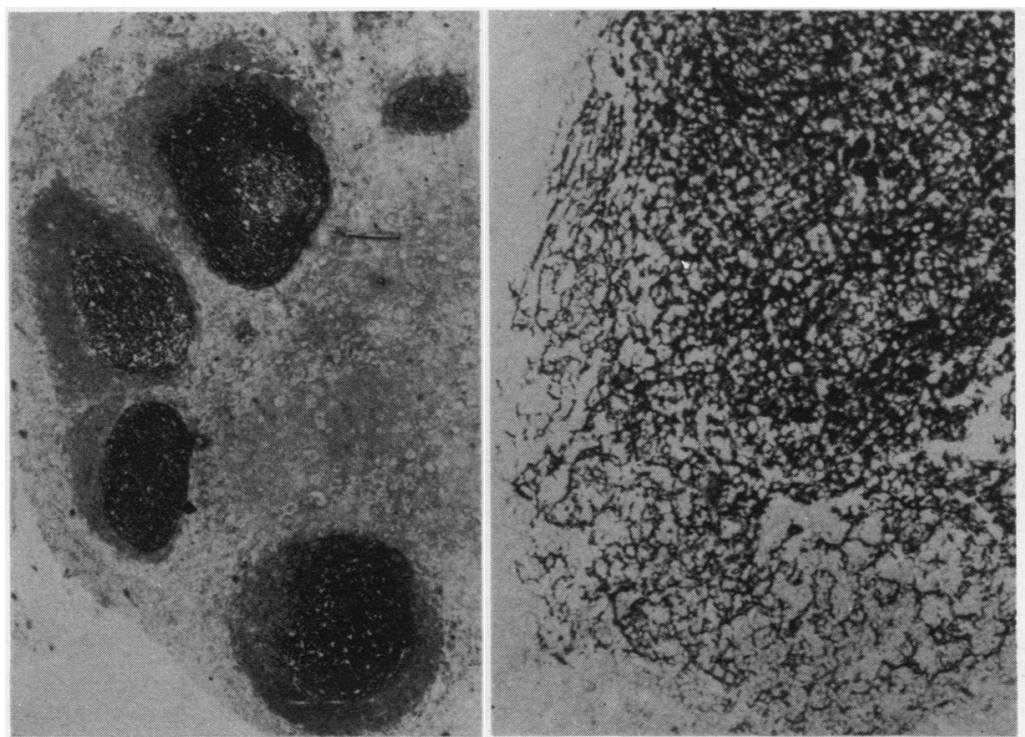

Fig. 1 (left) Immunoperoxidase staining of human tonsil (cryostat section) with antibody $R 4 / 23$ showing positive reactivity in lymphoid germinal centres. $\times 50$. (NB the small lymphocytes in the mantle zones which surround each germinal centre are not labelled with antibody R4/23; the dark appearance of these zones is due to haematoxylin staining of cell nuclei).

Fig. 2 (right) View of the periphery of a secondary follicle in lymphoid tissue (cryostat section) stained with antibody $R 4 / 23$, showing that the dendritic processes revealed by this antibody penetrate between the small lymphocytes of the mantle zone. $\times 150$. 

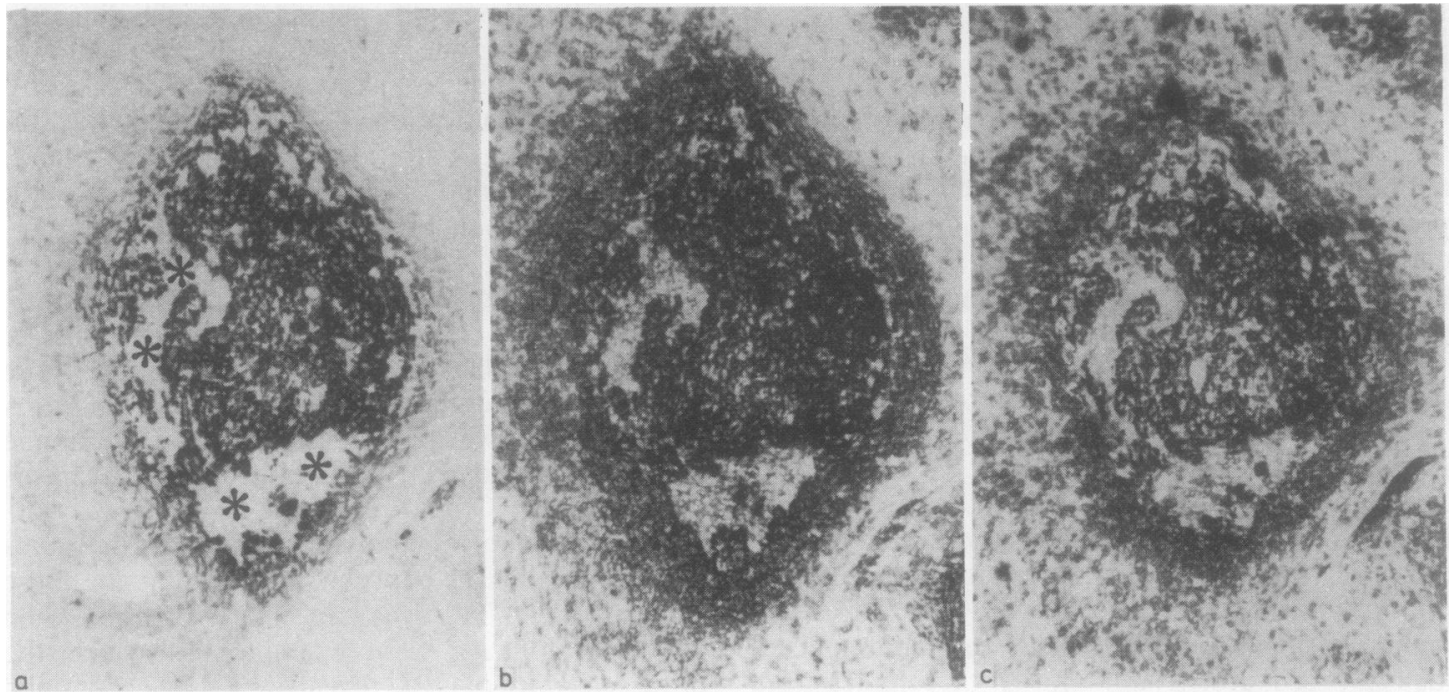

Fig. 3 Immunoperoxidase staining of consecutive cryostat sections of human tonsil with antibody R4/23, anti-IgM and anti-C3b receptor. A single follicle is illustrated in which (a) staining with $R 4 / 23$ shows irregularly shaped negative lacunae (asterisks); (b) staining for C3b receptor and (c) staining for IgM show very similar reaction patterns, providing evidence that antibody $R 4 / 23$ reacts with follicular dendritic reticulum cells. $\times 100$
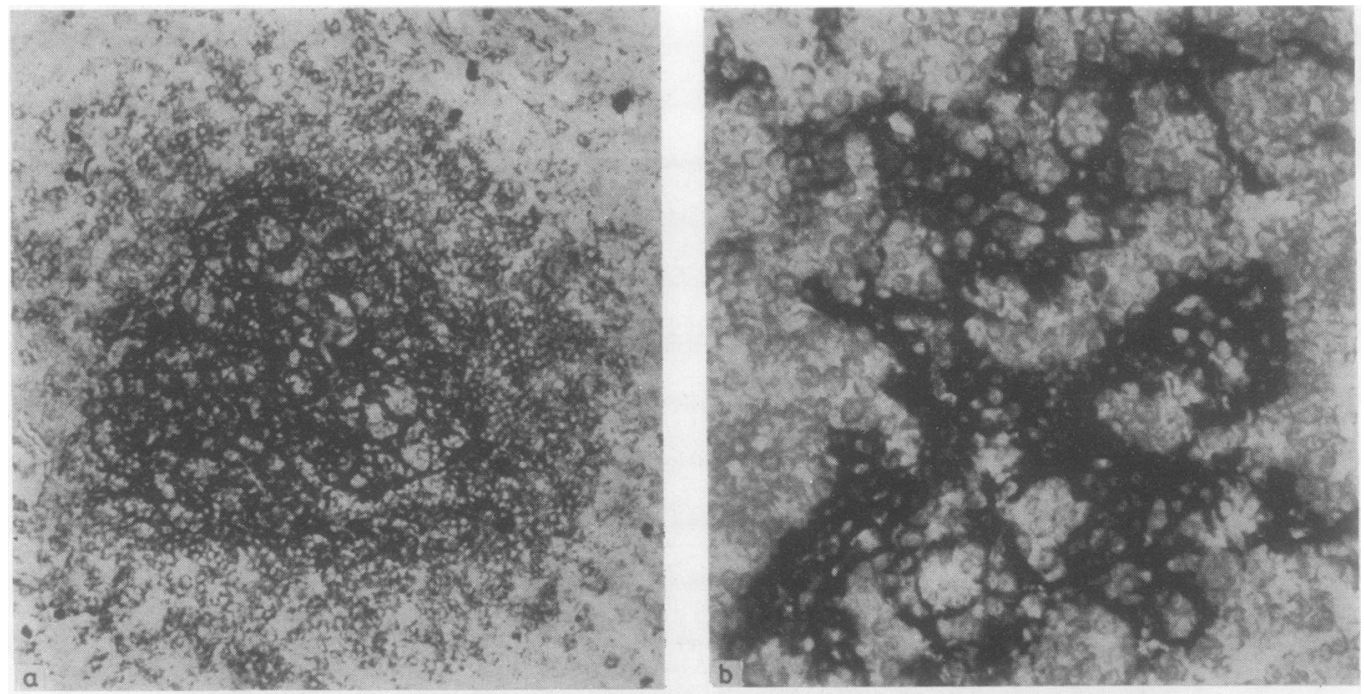

Fig. 4 (a) Staining of a section of normal spleen with antibody $R 4 / 23$ showing a strongly stained cluster of DRC within a $B$ cell follicle surrounded by more weakly labelled marginal zone lymphocytes. $\times 75$ (b) higher power view of DRC within a splenic B cell follicle. Note that the lymphoid cells present between the DRC are not themselves labelled $\times 200$

Lymphoid cells present within these follicles were completely unstained, but there was distinct, though weak, surface staining of the small lymphoid cells surrounding B cell follicles ("marginal zone cells"-Fig. 4).
150 cases of non-Hodgkin's lymphoma (NHL), 50 듀 cases of Hodgkin's disease, five cases of malignant $\stackrel{\oplus}{+}$ histiocytosis and four cases of histiocytosis X. The re- 7 sults indicated that the reactivity of $R 4 / 23$ was completely restricted to DRC present in these neoplasms. No other cells, such as neoplastic B cells, T cells, Reed-Sternberg or Hodgkin's cells, macrophages or histiocytosis X cells were reactive with R4/23. 

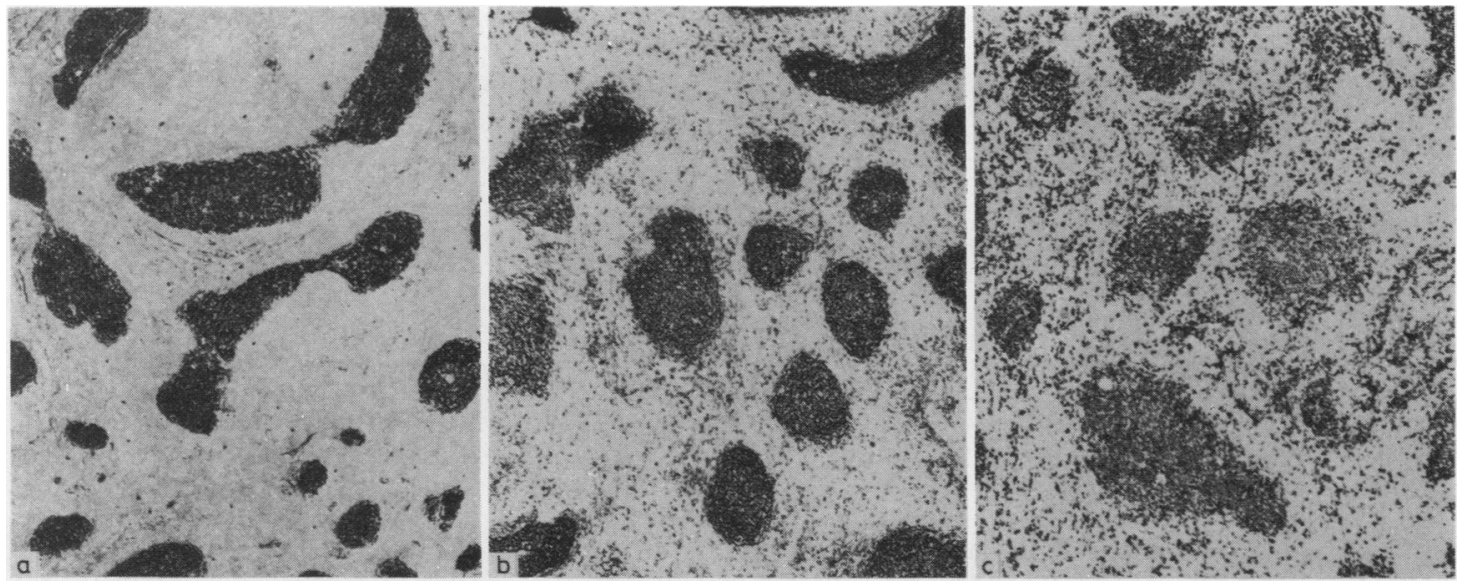

Fig. 5 Staining of two cases of follicular lymphoma (cryostat sections). In the first case (a) antibody R4/23 reveals an evenly distributed meshwork of DRC throughout the enlarged irregularly shaped neoplastic follicles; (b) staining for C3b receptor picks out this DRC pattern and also labels neoplastic $B$ cells. (c) labelling with the anti-B cell monoclonal antibody To15 stains neoplastic lymphoid cells, but does not react with DRC. $\times 65$
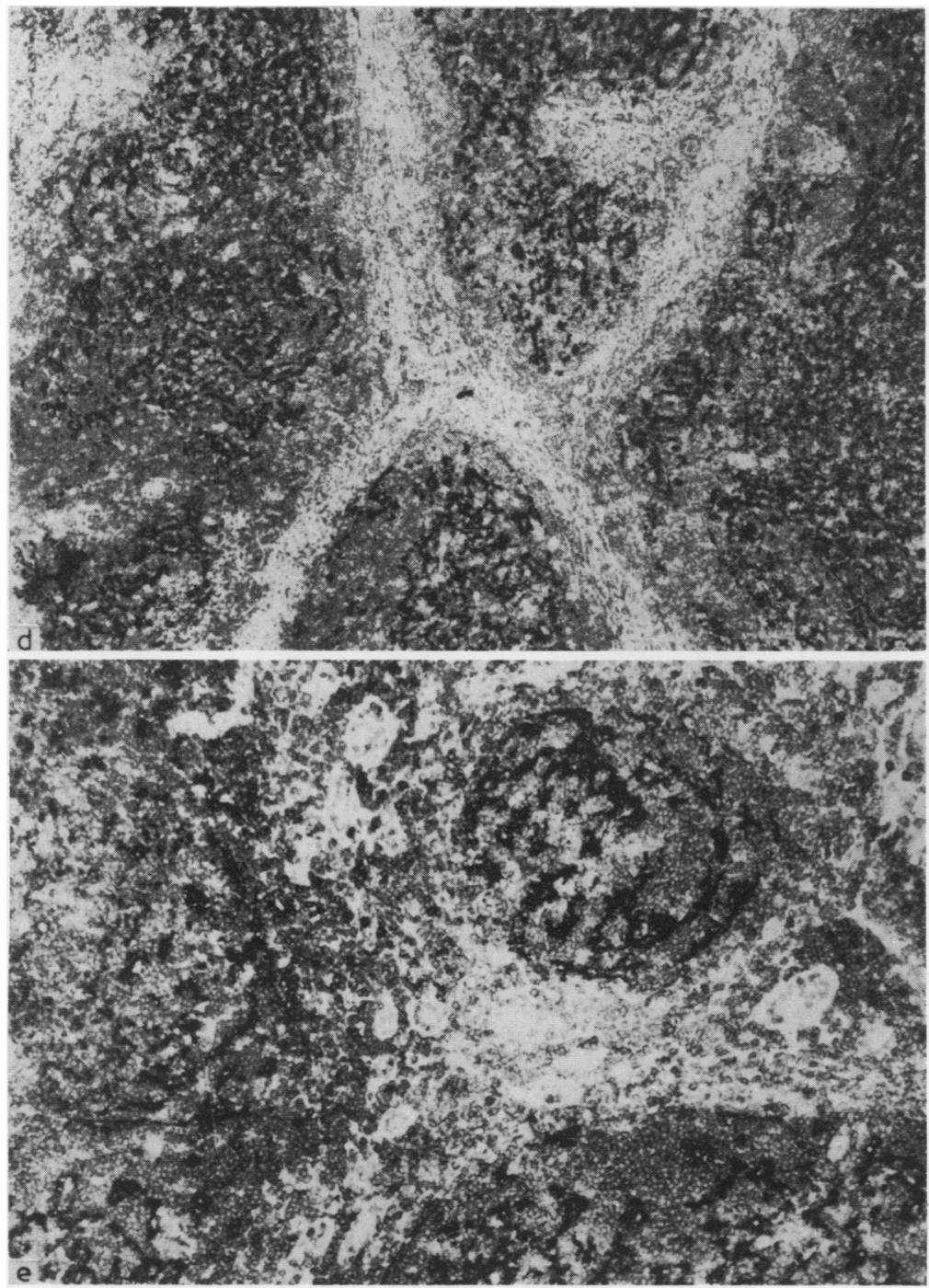

In the second case (d) staining with antibody $R 4 / 23$ shows a different pattern from that seen in the previous case, in that the DRC form a less dense meshwork and tend to be distributed in isolated clusters; (e) staining for $C 3 b$ receptor also reveals this DRC pattern together with weak labelling of neoplastic $B$ cells. $\times 90$ 

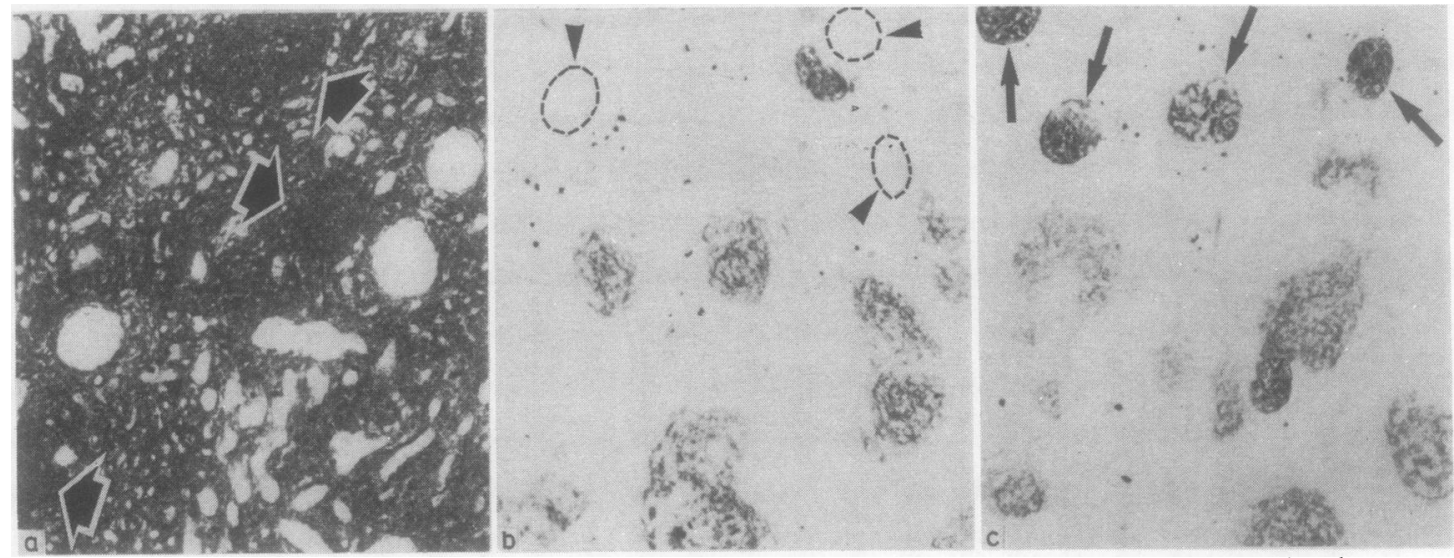

Fig. 6 Immunoperoxidase staining of sections from a kidney involved by follicular lymphoma using monoclonal antibodies against B-cells, DRC and C3b receptor. (a) The normal elements of the kidney (tubules and glomeruli) can be seen in the sections stained for $B$ cells as negative areas scattered among the dense infiltrate of lymphoma cells. In several areas the tendency of the lymphoma cells to form nodules (arrowed) can be seen; $(b)$ in the section stained with antibody $R 4 / 23$ clusters of DRC within these nodules are revealed. Note that in this section glomeruli (indicated by arrows and interrupted circles) are unstained; (c) in contrast anti-C3b receptor antibody delineates not only the clusters of DRC but also complement receptor on glomeruli (arrowed). $\times 65$

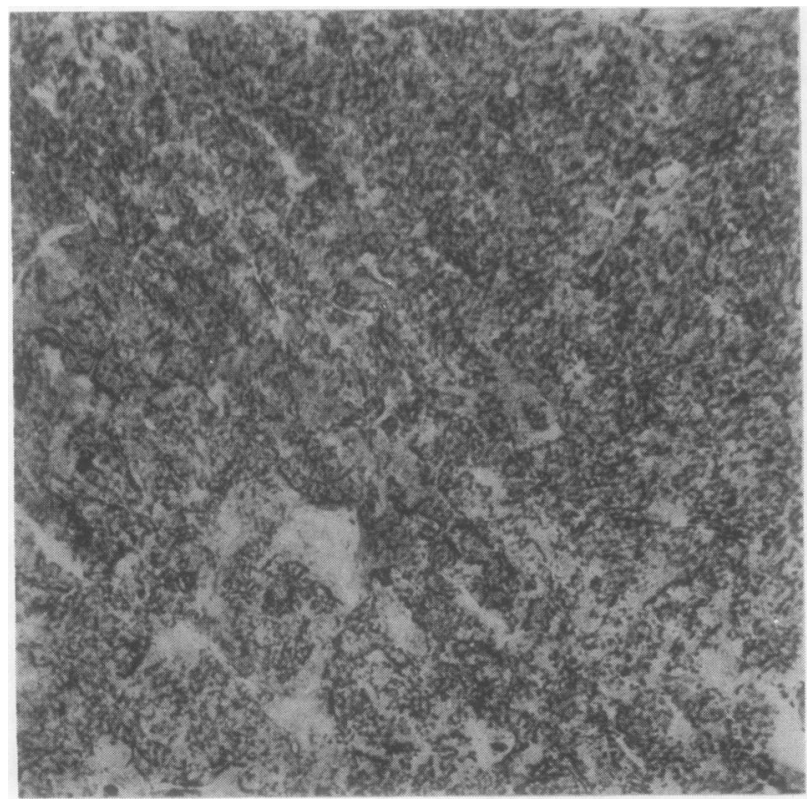

Fig. 7 Lymph node biopsy from a case of diffuse germinal centre-derived lymphoma (centrocytic lymphoma) stained with antibody $R 4 / 23$. A diffuse proliferation of strongly stained $D R C$ is revealed, without any evidence of a follicular pattern. $\times 65$

\section{NON-HODGKIN'S LYMPHOMA}

Germinal centre-derived lymphomas

In the majority of NHL in this category R4/23 staining revealed a more or less extensive proliferation of DRC throughout the tissue sample. There was considerable variation, however, in the staining patterns observed. In all germinal centrederived NHL showing a follicular growth patternthat is, centroblastic-centrocyticlymphoma-theneo- plastic follicles contained large numbers of DRC These were often present in a relatively sharply defined dense meshwork pattern very similar to thato seen in normal germinal centres (Fig. 5). In other cases of follicular lymphoma the DRC were lessodensely packed or were present in irregular clusters or clumps (Fig. 5), sometimes showing asymmetrical ${ }_{\mathbb{D}}^{+}$ distribution patterns within the germinal centres.

The biopsied tissue sample in all but one of the 

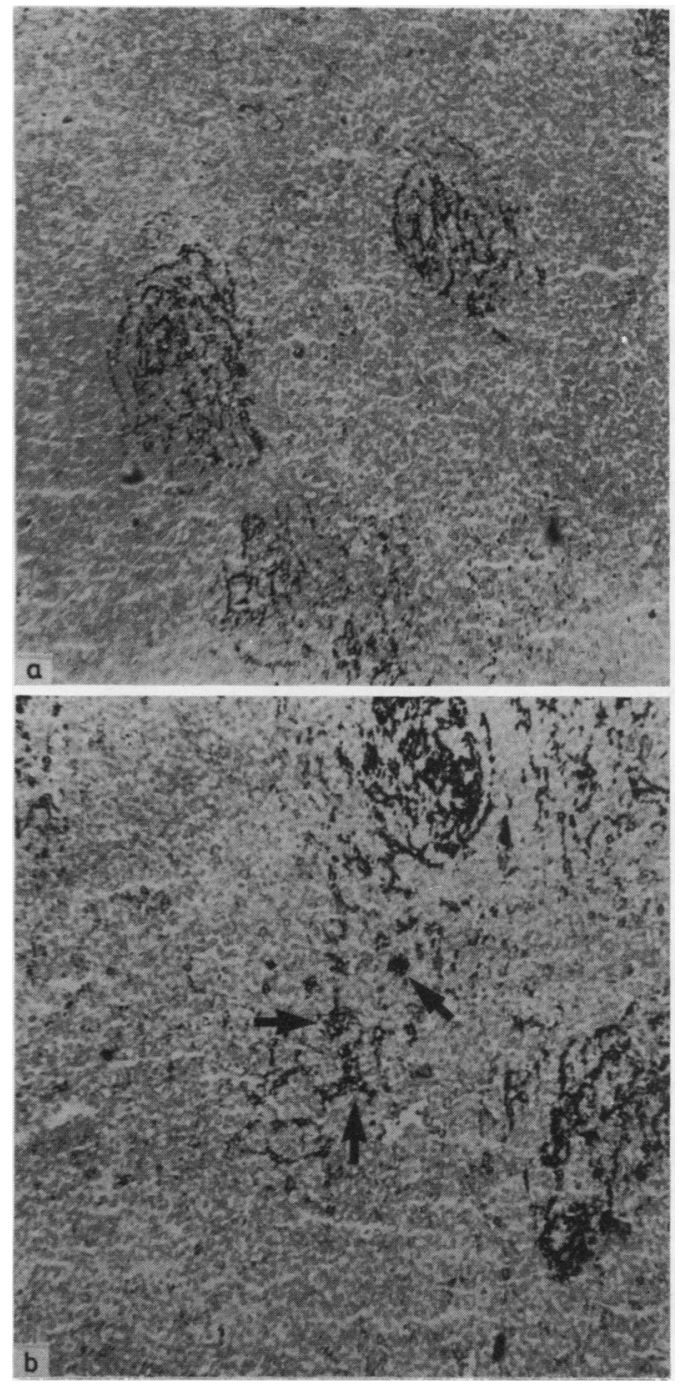

Fig. 8 Lymph node biopsy from a case of B cell chronic lymphocytic leukaemia (CLL) stained for DRC with (a) antibody $R 4 / 23$ and (b) for $C 3 b$ receptor. This case was the only one among 20 CLL biopsies in which such prominent $D R C$ clusters were detectable, the usual pattern being one of complete or near-complete obliteration of DRC. Note that staining for $C 3 b$ receptor reveals scattered histiocytes (arrowed) lying outside the DRC clusters. The neoplastic cells themselves are negative with both antibodies. $\times 50$

cases of follicular lymphoma consisted of a lymph node. The exception was a case of follicular lymphoma involving the kidney. In this biopsy the neoplastic cells showed a tendency to form nodular structures (most readily recognised when stained with monoclonal anti-B cell antibody-Fig. 6). Staining with $R 4 / 23$ revealed that many of these nodules contained a network of DRC (Fig. 6). These
DRC clusters could also be delineated by labelling with anti-C3b receptor (Fig. 6).

In cases of germinal centre cell-derived lymphomas of the centrocytic type showing a diffuse growth pattern, it was also possible to stain many DRC with antibody R4/23. The DRC in these cases formed a network, although this was not as sharply defined as in follicular centroblastic-centrocytic lymphoma (Fig. 7). When germinal centre cellderived lymphomas of centroblastic type were studied only two of six cases contained a network of DRC.

\section{$B$ cell lymphomas of non-germinal centre cell origin} In these cases staining with $R 4 / 23$ revealed very few or no detectable DRC. In those cases in which surviving areas of DRC staining could be identified, labelling for $\mathrm{C} 3 \mathrm{~b}$ receptor gave the same staining pattern as that observed with R4/23 (Fig. 8).

\section{HODGKIN'S DISEASE}

Two patterns of DRC distribution were observed when studying Hodgkin's disease. The commonest pattern, seen in all types of Hodgkin's disease with the exception of lymphocyte predominant Hodgkin's disease, was that DRC clusters were partially or totally obliterated by the disease process. However in four cases of lymphocyte predominant Hodgkin's disease there was marked expansion of B cell areas as recognised by staining for DRC and for $B$ cell markers.

All samples of Hodgkin's disease were carefully analysed to see whether antibody $R 4 / 23$ reacted with Reed-Sternberg or Hodgkin's cells, but in no instances was such staining observed.

\section{Discussion}

The data presented in this paper indicate that antibody R4/23 detects an antigen (or antigens) present in high density on DRC and, at a lower density, on a B cell subset. No other cell type in the human body was labelled with R4/23. In particular it was of interest that monocytes, macrophages, fibrocytes and fibroblasts were all negative. These findings argue against a close relation between these cells types and DRC. The immunohistological staining performed with $R 4 / 23$ does not give any hint as to the origin of DRC.

It was striking that DRC and/or their long cytoplasmic processes could be demonstrated with antibody R4/23 in the entire area of most (but not all) germinal centres, although often less densely in the centroblast-rich zone. This finding is in line with recent electron microscopic studies of Groscurth, ${ }^{18}$ but in contrast to results obtained with $5^{\prime}$-nucleo- 
tidase staining. ${ }^{8}$ With the latter enzyme, DRC and/or their cytoplasmic processes are usually demonstrable only in the centrocyte-rich and not in the centroblastrich zone of germinal centres. This observation suggests that the occurrence of $5^{\prime}$-nucleotidase is confined to the DRC present in the centrocyte-rich germinal centre zone and, therefore, that $5^{\prime}$-nucleotidase cannot be used as a pan-DRC marker.

It is notable that the $B$ cells located in the network of DRC were unreactive with R4/23, whereas the B cells in the DRC-deficient area just above the follicular mantle reacted with R4/23. This mutually exclusive expression of $R 4 / 23$ reactivity is particularly evident in the spleen. There, the $B$ cells within the network of DRC were R4/23-negative, whereas the $B$ cells located in the outer zone of the white pulp ("marginal zone") were distinctly R4/23-positive. The meaning of this pattern of antigen expression is not clear. The low density of the antigen on marginal zone cells and its absence from the B cells present in the area containing the DRC network allows, however, a nearly selective staining of DRC with $\mathrm{R} 4 / 23$. This is especially true for NHL, since in none of the NHL studied so far have the neoplastic cells themselves been stained with R4/23. ${ }^{19}{ }^{20}$ This finding suggests that R4/23-positive $B$ cells seldom give rise to lymphomas, or else that they lose the antigen during the process of transformation.

The immunohistological analysis of DRC with $\mathrm{R} 4 / 23$ in cases of non-Hodgkin's lymphoma (NHL) yielded interesting results. Samples from NHL of non-germinal centre cell-origin (chronic lymphocytic leukaemia of B type, hairy cell leukaemia, lymphoblastic lymphoma, immunoblastic lymphoma etc) contained no, or only a few, solitary DRC. The only exception was that in one of 20 cases of B cell chronic lymphocytic leukaemia larger surviving areas of DRC were found (Fig. 8). In contrast, all types of germinal centre cell-derived lymphomas (centroblastic-centrocytic, centrocytic and at least a few centroblastic) showed a more or less dense network of DRC with accumulations of neoplastic B cells between and around them. This was especially true in follicular centroblastic-centrocytic lymphoma, which constantly exhibited a nodular network of DRC (Fig. 5). Such an intimate association between DRC and neoplastic B cells appears to be pathognomonic for lymphomas derived from germinal centre cells.

The staining pattern obtained with R4/23 in the case of follicular non-Hodgkin's lymphoma infiltrating the kidney was of particular interest. The areas of lymphomatous infiltration were associated with clusters of DRC (Fig. 6). Since DRC are not normally present in renal tissue this suggests that DRC may migrate with the lymphoma (although they are presumably not themselves neoplastic) into the kidney. Alternatively it is possible that lymphoma cells which have infiltrated the kidney elicit the proliferation of DRC either from precursors already present in the kidney or from circulating DRC precursors. Future studies of other cases of extranodal lymphomas using antibody $R 4 / 23$ will be of considerable interest in analysing the relation between neoplastic germinal centre cells and DRC.

When Hodgkin's disease sections were stained $\overrightarrow{0}$ with R4/23 it was noteworthy that the only labelling occurred in B cell follicles. In many cases these were destroyed as part of the disease process, although as noted above, in lymphocyte predominant Hodgkin's disease a proliferation of B cell areas was noted. Of $\omega$ importance however is the fact that neither Reed- ? Sternberg nor Hodgkin's cells labelled with R4/23. This argues against the suggestion previously made by Curran and Jones ${ }^{21}$ on the basis of metallophil staining, that these cell types are closely related to DRC.

In conclusion antibody $\mathrm{R} 4 / 23$ provides a unique means of identifying DRC in human tissues, with a clarity which could not previously be achieved. Not $\overrightarrow{0}$ only will this prove of value in further immunohistological studies of reactive and neoplastic lymphoid tissue, but should also shed light upon the origin and distribution of DRC in fetal tissues. Furthermore preliminary experiments have shown that cell suspensions from human lymphoid tissue contain a significant proportion of DRC (as identified with antibody R4/23). It is therefore likely that it will be possible to enrich this cell population by affinity immunoabsorption techniques in sufficient quantities to analyse the antigen which R4/23 recognises and also to produce new monoclonal antibodies to this cell type and thereby to study its functional influence on the immune response in vitro.

This work was supported by the Leukaemia Research Fund, the Deutsche Forschungsgemein- 은 schaft, SFB111, D8 and CL1 and by a Medical Research Council Studentship. We are grateful to Mrs JL Cordell, Miss R-E Woolston, Miss A

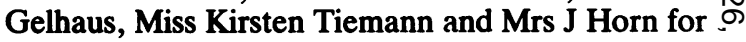
skilful technical assistance, and to Dr PCL Beverley N for the gift of monoclonal antibody UCHT1. N

\section{References}

${ }^{1}$ Maximov A. Bindegewebe und blutbildende Gewebe. In: von Möllendorff W, ed. Handbuch der mikroskopischen Anatomie des Menschen. Berlin: Springer, 1927; 232-583.

2 Milanesi S. Sulla presenza di dispositivi di giunzione tra le cellule dendritiche dei follicoli linfatici del linfonodo. Boll Soc Ital Biol Sper 1965;41:1223.

${ }^{3}$ Mori Y, Lennert K. Electron microscopic atlas of lymph node 
cytology and pathology. Berlin, Heidelberg, New York: Springer, 1969.

${ }^{4}$ Müller-Hermelink HK, Lennert K. The cytologic, histologic, and functional basis for a modern classification of lymphomas. In: Lennert $\mathbf{K}$, ed. in collaboration with Stein $\mathbf{H}$, Mohri $\mathbf{N}$, Kaiserling E, Müller-Hermelink HK. Malignant lymphomas other than Hodgkin's disease. New York, Heidelberg, Berlin: Springer, 1978: 1-71.

${ }^{5}$ Swartzendruber DC. Desmosomes in germinal centers of mouse spleen. Exp Cell Res. 1965;40:429.

${ }^{6}$ Swartzendruber DC. Observations on the ultrastructure of lymphatic tissue germinal centers. In: Cottier $\mathrm{H}$, Odartchenko $\mathrm{N}$, Schindler $\mathrm{R}$, Congdon CC, eds. Germinal centers in immune responses. Berlin, Heidelberg, New York: Springer, 1967:71-6.

${ }^{7}$ Nossal GJV, Ada GL. Antigens, lymphoid cells and the immune response. New York, London: Academic Press, 1971.

${ }^{8}$ Lennert K, Kaiserling E, Müller-Hermelink HK. Malignant lymphomas: Models of differentiation and co-operation of lymphoreticular cells. In: Clarkson B, Marks PA, Till JE. eds. Differentiation of normal and neoplastic hematopoietic cells, Book B. Cold Spring Harbor Conferences on Cell Proliferation, Vol 5, Cold Spring Harbor Laboratory, Cold Spring Harbor: 1978:897-913.

${ }^{9}$ Müller-Hermelink HK. Characterization of the B-cell and T-cell regions of human lymphatic tissue through enzyme histochemical demonstration of ATPase and 5'nucleotidase activities. Virchows Arch B Cell Pathol 1974;16:371.

${ }^{10}$ Gerdes J, Klatt U, Stein H. Xenoantiserum to human C3 receptors: its preparation and effect on the $\mathrm{C} 3 \mathrm{~b}$ and $\mathrm{C} 3 \mathrm{~d}$ receptors of tonsil cells and the $\mathrm{C} 3 \mathrm{~b}$ receptors of erythrocytes and neutrophils. Immunology 1980;39:75.

${ }^{11}$ Dalchau R, Kirkley J, Fabre JW. Monoclonal antibody to a human leukocyte specific membrane glycoprotein probably homologous to the leukocyte-common (L-C) antigen of the rat. Eur J Immunol 1980;10:737.

${ }^{12}$ Gerdes J, Naiem M, Mason DY, Stein H. Human complement (C3b) receptors defined by a mouse monoclonal antibody. Immunology 1982;45:645.
${ }^{13}$ Naiem M, Gerdes J, Abdulaziz Z, Nash JRG, Stein H, Mason DY. Production of monoclonal antibodies for the immunohistochemical analysis of human lymphoma. In: Knapp W, ed. Leukaemia markers. New York, London: Academic Press, 1981:117.

${ }^{14}$ Beverley PCL, Callard RE. Distinctive functional characteristics of human " $T$ " lymphocytes defined by $E$ rosetting and a monoclonal anti-T cell antibody. Eur J Immunol 1981;11:329.

${ }^{15}$ Graham RC Jr,Karnovsky MJ. The early stages of absorption of injected horseradish peroxidase in the proximal tubules of mouse kidney: ultrastructural cytochemistry by a new technique. J Histochem Cytochem 1966;14:291.

${ }^{16}$ Gajl-Peczalska KJ, Fish AJ, Meuwissen HJ, Frommel D, Good RA. Localization of immunological complexes fixing $B_{1 c}(C 3)$ in germinal centers of lymph nodes. J Exp Med 1969;130:1367.

${ }^{17}$ Gerdes J, Stein H. Complement (C3) receptors on dendritic reticulum cells of normal and malignant lymphoid tissue. Clin Exp Immunol 1982;48:348.

${ }^{18}$ Groscurth P. Non-lymphatic cells in the lymph node cortex of the mouse. I. Morphology and distribution of the interdigitating cells and the dendritic reticular cells in the mesenteric lymph node of the adult ICR mouse. Pathol Res Pract 1980;169:212.

${ }^{19}$ Stein H, Lennert K, Mason DY, et al. Morphology and immunohistology of malignant lymphomas. In: Comparative research on leukaemia and related diseases. New York: Elsevier North Holland, 1981.

${ }^{20}$ Stein H, Mason DY, Gerdes J, et al. Immunohistology of B cell lymphomas. In: Knapp W, ed. Leukaemia markers. London: Academic Press, 1981:99-108.

${ }^{21}$ Curran RC, Jones EL. Hodgkin's disease: an immunohistochemical and histological study. J Pathol 1978;125:39.

Dr DY Mason, Haematology Department, John Radcliffe Hospital, Oxford OX3 9DU, England. 